\title{
Cannabinoid Effects on CB1 Receptor Density in the Adolescent Brain: An Autoradiographic Study Using the Synthetic Cannabinoid HU210
}

\author{
VICTORIA S. DALTON ${ }^{1,2 *}$ AND KATERINA ZAVITSANOU ${ }^{1,2}$ \\ ${ }^{1}$ Schizophrenia Research Institute, Sydney, Australia \\ ${ }^{2}$ ANSTO LifeSciences, Australian Nuclear Science and Technology Organisation, Sydney, Australia
}

KEY WORDS adolescence; adult; neuroadaptation; rat; autoradiography; $\left[{ }^{3} \mathrm{H}\right]$ CP55,940

\begin{abstract}
The short- and long-term behavioral effects of cannabinoids differ in adolescent and adult rodents. Few studies though have examined the underlying neurochemical changes that occur in the brain following adolescent cannabinoid exposure. In this study, we examined the effect of treatment with the synthetic cannabinoid, HU210, on $\mathrm{CB} 1$ receptor density in the brain and on body weight in adolescent male rats. Rats were treated daily with 25,50 , or $100 \mu \mathrm{g} / \mathrm{kg}$ HU210 for 4 or 14 days, or received a single dose of $100 \mu \mathrm{g} / \mathrm{kg}$ HU210 and sacrificed $24 \mathrm{~h}$ later. Receptor density was investigated using in vitro autoradiography with the $\mathrm{CB} 1$ receptor ligand $\left[{ }^{3} \mathrm{H}\right] \mathrm{CP} 55,940$. In contrast to adult animals treated under the same paradigm in a previous study, adolescents continued on average, to gain weight over the course of the study. Weight gain was slowest in the $100 \mu \mathrm{g} / \mathrm{kg}$ group and improved dose dependently with controls gaining the most weight. Following the acute dose of HU210, a trend for a reduction in $\left[{ }^{3} \mathrm{H}\right] \mathrm{CP55}, 940$ binding and a significant effect of treatment was observed. Statistically significant, dosedependent, region-specific decreases in binding were observed in all brain regions examined following 4 and 14 days treatment. The pattern of CB1 receptor downregulation was similar to that observed in adults treated with cannabinoids in previous studies; however, its magnitude was smaller in adolescents. This reduced compensatory response may contribute to some acute behavioral effects, the pharmacological cross-tolerance and the long-lasting, adverse psychological consequences of cannabinoid exposure during adolescence. Synapse 64:845-854, 2010. $\odot 2010$ Wiley-Liss, Inc.
\end{abstract}

\section{INTRODUCTION}

Adolescence is a critical period of development during the transition from childhood to adulthood (Andersen, 2003; Spear, 2000). It is a period when the brain undergoes both progressive and regressive changes including extensive synaptic remodelling and pruning and alterations in neurotransmitters and their receptors in cortical and limbic brain regions across different species (Andersen, 2003; Spear, 2000). These alterations provide a biological basis for the unique adolescent behaviors including an increase in risk taking often manifesting in experimentation with psychoactive substances (Realini et al., 2009; Spear, 2000). Initiation of substance use during adolescence is linked in some cases with unfavorable outcomes such as lifetime drug addiction and development of psychosis (Chambers et al., 2003; Izenwasser, 2005; Luzi et al., 2008; Realini et al., 2009).

Cannabis is one of the most widely used street drugs worldwide by adolescent teenagers (Rubino and Parolaro, 2008). Cannabinoid derivatives are used medicinally to treat conditions such as nausea, vomiting, and acute and tonic pain (Wang et al., 2008). They have also been proposed for use as appetite stimulants to treat

\footnotetext{
Contract grant sponsor: Schizophrenia Research Institute (SRI), Australia; Australian Nuclear Science and Technology Organisation

*Correspondence to: Victoria Dalton, Radiopharmaceuticals Research Institute, ANSTO, PMB 1 Menai, NSW 2234, Australia. E-mail: victoria.dalton@ ansto.gov.au

Received 16 November 2009; Accepted 14 March 2010

DOI 10.1002/syn.20801

Published online 29 March 2010 in Wiley Online Library (wileyonlinelibrary. com).
} 
anorexia nervosa (Fride et al., 2005), a condition which predominantly affects adolescents (Sigel, 2008). However, cannabis use during adolescence is associated with the development of attentional deficits, cognitive impairment and psychoses such as schizophrenia (Luzi et al., 2008; Rubino and Parolaro, 2008; Schneider, 2008). The main active component of cannabis, $\Delta^{9}$ - tetrahydrocannabinol (THC), produces most of its psychoactive effects by interacting with specific cannabinoid receptors $(\mathrm{CB} 1)$ in the brain. These receptors are also activated by endocannabinoids that occur naturally in the brain (such as anandamide) and constitute part of the endocannabinoid system that modulates the release of both excitatory and inhibitory neurotransmitters in many brain regions (Wilson and Nicoll, 2002) and is thought to be involved in processes such as short- and long-term synaptic plasticity, attention, cognition, and control of movement (Breivogel and Childers, 1998; Ledent et al., 1999; Pattij et al., 2008; Romero et al., 2002a; Wilson and Nicoll, 2002; Zimmer et al., 1999).

Studies suggest that the short-term behavioral effects of THC differ in adolescent and adult animals. Adolescent rodents find THC less aversive than adults in place and taste aversion tests (Quinn et al., 2008; Schramm-Sapyta et al., 2007) and emit less vocalizations than adults during handling following THC exposure (Quinn et al., 2008). THC also appears to have greater anxiogenic and locomotor-reducing effects in adult rats than in adolescents (Schramm-Sapyta et al., 2007; Wiley et al., 2007). Novelty seeking is suppressed in adults but not adolescents after an acute dose of WIN 55,212-2 (Fox et al., 2009). Effects of acute WIN 55,212-2 treatment such as impairments in object and social recognition memory, altered social play and inadequate self-grooming are more pronounced in adolescents than in adults (Schneider et al., 2008).

The longer-term consequences of cannabinoid exposure are also distinct in adults and adolescents (Ehrenreich et al., 1999; Luzi et al., 2008). Work in humans for example identified the presence of attentional deficits in adulthood in early (before age 16) but not late-onset cannabis users (Ehrenreich et al., 1999). Furthermore, epidemiological studies in humans have identified a link between cannabis use during adolescence with the later development of psychoses such as schizophrenia (Luzi et al., 2008). In animal studies, behavioral tests indicate that chronic cannabinoid treatment during adolescence leads to deficits in object and social recognition, social behavior, working memory and prepulse inhibition, effects not seen in adults when treated in parallel (O'Shea et al., 2004; Quinn et al., 2008; Schneider and Koch, 2003; Schneider et al., 2008).

The underlying neurochemical mechanisms for the differential behavioral effects of cannabinoids between adolescents and adults are unclear and merit further investigation especially in view of both the beneficial (e.g. appetite stimulation) and detrimental (onset of psy- chosis) effects of cannabinoids during adolescence (Rubino and Parolaro, 2008; Trezza et al., 2008). We have previously shown that administration of the potent synthetic cannabinoid HU210 (Mechoulam et al., 1988; Ottani and Giuliani, 2001), dose dependently downregulates cannabinoid CB1 receptors in the brain of adult animals and this downregulation strongly correlates with body weight loss (Dalton et al., 2009).

The aim of this study was to examine the timecourse of CB1 receptor adaptation in the adolescent male rat brain following the same treatment regime as described in Dalton et al. (2009). We describe the effects of subchronic and chronic treatment with three doses of HU210, on CB1 receptor density in the adolescent male rat brain as well as the effects of a single, acute, high-dose of the drug. The effects of HU210 on body weight were also investigated.

\section{MATERIALS AND METHODS Animals}

Adolescent male Wistar rats were obtained from the Animal Resource Centre Pty Ltd (Perth, Australia) and were housed in polyethylene boxes with wire lids $\left(489 \times 343 \times 240 \mathrm{~mm}^{3}\right)$ in groups of three to four per cage. All handling of animals and procedures were carried out in accordance with the guidelines established by the Animal Care and Ethics Committee at the Australian Nuclear Science and Technology Organisation. The animals were kept at a constant temperature of $22 \pm 2{ }^{\circ} \mathrm{C}$ on a $12-12 \mathrm{~h}$ light-dark cycle with lights on at 09.00 am and were handled during the seven days preceding the experiment. Food and water were freely available. Cohort one consisted of 30 rats with body weights ranging between $127.6 \pm 13 \mathrm{~g}$ on postnatal (PND) 35. Cohort two was made up of a total of 24 rats with an initial body weight $122.9 \pm 10 \mathrm{~g}$ on PND 35 .

\section{Drugs and treatment}

Animals from cohort one were divided into five treatment groups ( $n=6$ per group) so that the mean body weight and standard deviation for each group were approximately equal at the beginning of the experiment. The synthetic cannabinoid, HU210, was obtained from Sapphire Laboratories, Australia and was dissolved in a vehicle solution of Tween 80:dimethyl sulfoxide:normal saline (1:1:98). Animals in groups 1-3 were treated daily for four days by intraperitoneal (i.p.) injection with the following doses of HU210: 25, 50, or $100 \mu \mathrm{g} / \mathrm{kg}$. A fourth group received vehicle for three days and $100 \mu \mathrm{g} / \mathrm{kg}$ HU210 on Day 4. Control rats received only vehicle solution for the treatment period. Animals in cohort two were divided into four groups ( $n=6$ per group). Groups $1-3$ received daily i.p. injections of 25,50 , or $100 \mu \mathrm{g} / \mathrm{kg}$ HU210 for 14 days. The control group was injected with vehicle only for 14 days. For both cohorts, animals were weighed daily prior to injection. All injections were 


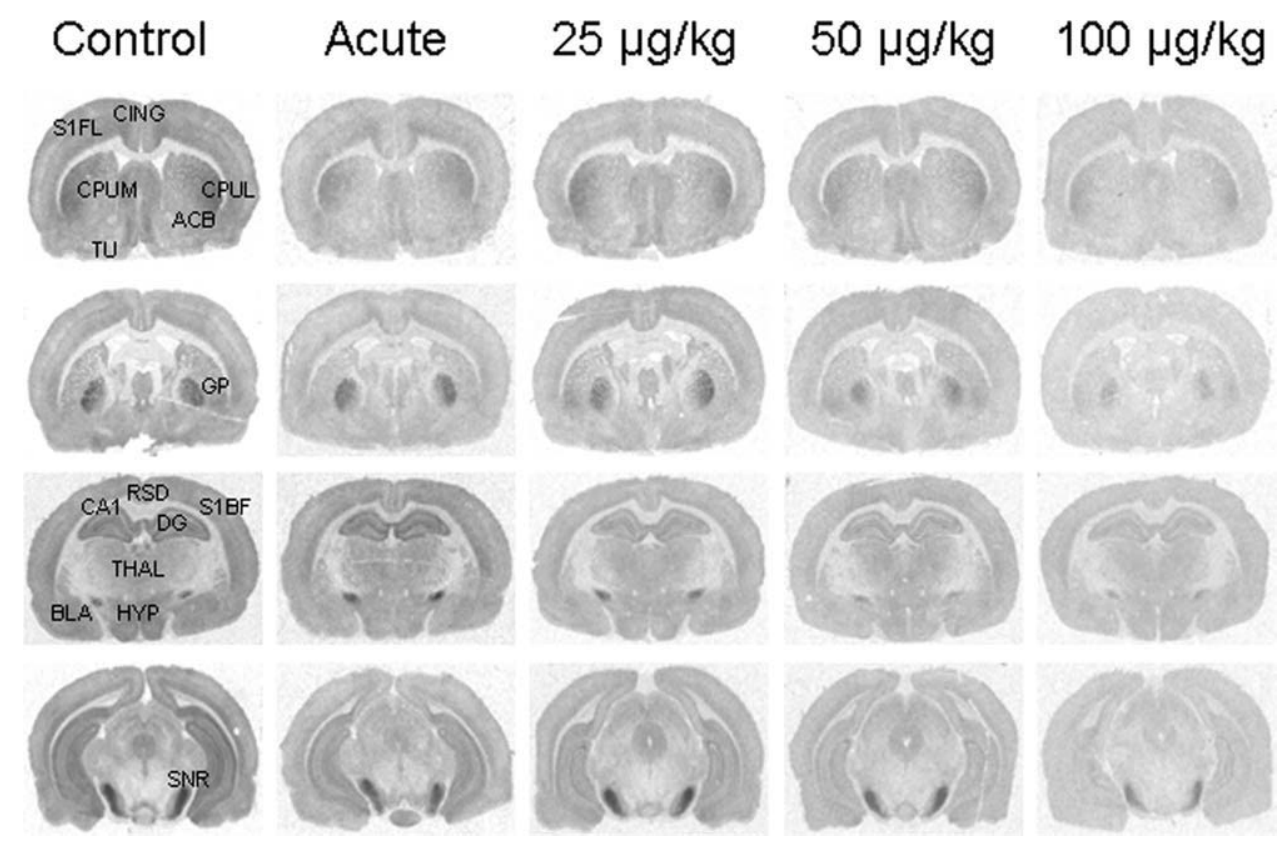

Fig. 1. Typical autoradiographs showing $\left[{ }^{3} \mathrm{H}\right] \mathrm{CP} 55,940$ binding in adolescent animals treated with vehicle which consisted of Tween 80:dimethyl sulfoxide:normal saline (1:1:98) for 14 days (control), received a single dose of $100 \mu \mathrm{g} / \mathrm{kg}$ HU210 (acute) or 25,50 , or $100 \mu \mathrm{g} / \mathrm{kg}$ doses of HU210 for 14 days. ACB, nucleus accumbens; $\mathrm{BLA}$, basolateral amygdala; CA1, CA1 region of the hippocampus;

administered at a volume of $1 \mathrm{ml} / \mathrm{kg}$. As for other autoradiography studies examining cannabinoid receptor levels/activity following cannabinoid treatment (Romero et al., 1998; Breivogel et al., 1999; Sim-Selley and Martin, 2002), animals were euthanized $24 \mathrm{~h}$ after the last injection in order to allow drug washout. Brains were removed and frozen rapidly in liquid nitrogen. Coronal brain sections $(16 \mu \mathrm{m})$ were cut with a cryostat and thaw mounted onto microscope slides.

\section{Autoradiography}

$\left[{ }^{3} \mathrm{H}\right] \mathrm{CP5} 5,940$ binding was carried out as described in Dalton et al. (2009). Briefly, sections were preincubated for $30 \mathrm{~min}$ at room temperature in $50 \mathrm{mM}$ Tris $\mathrm{HCl}$ ( $\mathrm{pH}$ 7.4) containing $5 \%$ bovine serum albumin (BSA). Sections were then incubated for $2 \mathrm{~h}$ at room temperature in the same buffer with the addition of $5 \mathrm{nM}\left[{ }^{3} \mathrm{H}\right]$ CP55,940 (specific activity $139.6 \mathrm{Ci} / \mathrm{mmol}$, Perkin Elmer, USA). Nonspecific binding was determined by incubating adjacent sections in $5 \mathrm{nM}\left[{ }^{3} \mathrm{H}\right] \mathrm{CP} 55,940$ in the presence of $10 \mu \mathrm{M}$ CP55,940. After the incubation, sections were washed for one hour at $4^{\circ} \mathrm{C}$ in $50 \mathrm{mM}$ Tris $\mathrm{HCl}(\mathrm{pH}$ 7.4.) containing $1 \% \mathrm{BSA}$ and a second wash was then carried out for three hours in the same buffer at $4^{\circ} \mathrm{C}$. The third wash was in $50 \mathrm{mM}$ Tris $\mathrm{HCl}(\mathrm{pH}$ 7.4.) for $5 \mathrm{~min}$ at $4^{\circ} \mathrm{C}$. Sections were then dipped briefly in ice cold distilled water and then dried.

Following the assay, dried sections were apposed to Kodak Biomax MR film, together with autoradio-
CING, cingulate cortex; CPUL, lateral caudate putamen; CPUM, medial caudate putamen; DG, dentate gyrus; GP, globus pallidus; HYP, hypothalamus; RSD, retrospenial cortex; S1BF, primary somatosensory cortex (barrel field); S1FL, primary somatosensory cortex (forelimb field); SNR, substantia nigra; THAL, thalamus; TU, olfactory tubercle nucleus.

graphic standards $\left(\left[{ }^{3} \mathrm{H}\right]\right.$ microscales from Amersham), in x-ray film cassettes. Films were developed after 69 days using Kodak GBX developer and fixed with Kodak GBX fixer.

\section{Quantitative analysis of autoradiographic images}

All films were analyzed by using a computer-assisted image analysis system, Multi-Analyst, connected to a GS-690 Imaging Densitometer (Bio-Rad, USA). Brain regions for quantification were identified based on a standard rat brain atlas (Paxinos and Watson, 2007). As detailed in Figure 1, 15 brain regions were selected for quantification. Quantification of receptor binding in each brain region was performed by measuring the average optical density in adjacent brain sections. Nonspecific binding was subtracted from the total binding to determine the specific binding. Optical density measurements for specific binding were then converted into fmoles $\left[{ }^{3} \mathrm{H}\right] \mathrm{CP} 55,940$ per $\mathrm{mg}$ tissue equivalent (fmol/mg TE), according to the calibration curve obtained from the tritium standards.

\section{Data analysis}

Two-way ANOVA (treatment $\times$ brain region) with repeated measures was carried out to identify statistically significant variation in radioligand binding in 15 brain regions, across groups treated for 4 or 14 days. 
TABLE I. Absolute values for $\left[{ }^{3} \mathrm{H}\right] \mathrm{CP55,940}$ binding in fmoles / $\mathrm{mg}$ tissue equivalent for adolescent rats that received vehicle, a single acute dose of $100 \mu \mathrm{g} / \mathrm{kg}$ HU210 or that were treated with doses of 25, 50, or $100 \mathrm{\mu g} / \mathrm{kg}$ HU210 daily for 4 or 14 days

\begin{tabular}{|c|c|c|c|c|c|c|c|c|c|}
\hline & \multicolumn{5}{|c|}{4 Days } & \multicolumn{4}{|c|}{14 Days } \\
\hline & Vehicle & Acute (100) & 25 & 50 & 100 & Vehicle & 25 & 50 & 100 \\
\hline S1BF & $38.9 \pm 1.3$ & $27.5 \pm 2.3$ & $26.1 \pm 2.9$ & $23.9 \pm 1.7$ & $19.8 \pm 2.1^{*}$ & $49.7 \pm 2.0$ & $28.1 \pm 0.7^{\S}$ & $20.8 \pm 1.5^{\#}$ & $17.6 \pm 1.8^{\#}$ \\
\hline RSD & $35.6 \pm 2.4$ & $24.6 \pm 1.9$ & $25.7 \pm 3.2$ & $21.4 \pm 1.9$ & $17.9 \pm 1.9$ & $45.8 \pm 2.6$ & $27.0 \pm 1.4^{*}$ & $20.6 \pm 1.6^{\#}$ & $17.2 \pm 1.1^{\#}$ \\
\hline S1FL & $46.7 \pm 1.5$ & $32.6 \pm 2.9$ & $34.0 \pm 1.2$ & $29.4 \pm 2.0$ & $23.1 \pm 2.7^{\S}$ & $58.5 \pm 1.1$ & $32.7 \pm 1.5^{\#}$ & $33.2 \pm 4.8^{\#}$ & $17.6 \pm 2.6^{\#}$ \\
\hline CING & $45.4 \pm 2.0$ & $33.5 \pm 3.7$ & $33.0 \pm 1.1$ & $28.1 \pm 2.0$ & $23.7 \pm 2.9^{\S}$ & $58.2 \pm 2.6$ & $34.4 \pm 1.6^{\S}$ & $29.1 \pm 3.6^{\#}$ & $19.6 \pm 2.3^{\#}$ \\
\hline $\mathrm{ACB}$ & $36.8 \pm 1.9$ & $26.7 \pm 2.8$ & $29.1 \pm 1.3$ & $22.9 \pm 1.6$ & $17.7 \pm 1.9^{*}$ & $47.5 \pm 1.7$ & $27.0 \pm 1.2^{*}$ & $19.8 \pm 2.4^{\#}$ & $13.4 \pm 2.6^{\#}$ \\
\hline CPUM & $49.5 \pm 3.2$ & $39.0 \pm 3.6$ & $40.7 \pm 2.1$ & $30.8 \pm 2.1^{*}$ & $25.0 \pm 2.6^{\S}$ & $58.6 \pm 2.6$ & $37.9 \pm 1.1^{*}$ & $31.0 \pm 3.1^{\#}$ & $20.8 \pm 2.9^{\#}$ \\
\hline CPUL & $83.7 \pm 4.3$ & $66.7 \pm 5.2^{*}$ & $69.7 \pm 2.8$ & $51.9 \pm 2.9^{\#}$ & $42.3 \pm 4.2^{\#}$ & $113.0 \pm 2.8$ & $70.3 \pm 2.5^{\#}$ & $55.7 \pm 4.8^{\#}$ & $39.2 \pm 4.5^{\#}$ \\
\hline GP & $115.0 \pm 3.9$ & $105.0 \pm 9.3$ & $98.5 \pm 3.5$ & $83.1 \pm 2.6^{\#}$ & $70.2 \pm 6.5^{\#}$ & $108.9 \pm 7.5$ & $84.3 \pm 4.4^{\S}$ & $57.2 \pm 4.4^{\#}$ & $35.6 \pm 2.5^{\#}$ \\
\hline SNR & $208.5 \pm 8.2$ & $192.7 \pm 9.1$ & $168.0 \pm 19.5^{\#}$ & $157.4 \pm 10.7^{\#}$ & $126.8 \pm 11.9^{\#}$ & $239.9 \pm 10.9$ & $188.5 \pm 16.3^{\#}$ & $109.8 \pm 15.7^{\#}$ & $60.1 \pm 3.6^{\#}$ \\
\hline BLA & $38.1 \pm 2.0$ & $28.7 \pm 2.5$ & $27.9 \pm 2.6$ & $22.1 \pm 1.0$ & $17.9 \pm 1.9^{*}$ & $63.2 \pm 3.1$ & $36.6 \pm 3.2^{\#}$ & $25.1 \pm 1.5^{\#}$ & $19.6 \pm 1.9^{\#}$ \\
\hline HYP & $48.5 \pm 1.1$ & $34.2 \pm 3.4$ & $33.3 \pm 2.9$ & $26.2 \pm 0.6^{\S}$ & $22.3 \pm 2.2^{\#}$ & $76.3 \pm 6.4$ & $35.3 \pm 3.3^{\#}$ & $24.8 \pm 0.8^{\#}$ & $17.0 \pm 2.7^{\#}$ \\
\hline TU & $33.8 \pm 2.0$ & $26.2 \pm 2.9$ & $27.1 \pm 1.5$ & $23.9 \pm 2.3$ & $18.0 \pm 2.4$ & $46.1 \pm 1.6$ & $28.7 \pm 2.3$ & $20.8 \pm 2.2^{\#}$ & $15.1 \pm 2.2^{\#}$ \\
\hline THAL & $38.8 \pm 2.2$ & $31.1 \pm 3.3$ & $34.0 \pm 2.6$ & $27.3 \pm 2.0$ & $26.0 \pm 2.8$ & $47.1 \pm 3.1$ & $37.4 \pm 2.1$ & $31.7 \pm 0.8$ & $23.1 \pm 2.1^{\S}$ \\
\hline CA1 & $67.9 \pm 3.4$ & $51.9 \pm 4.0$ & $49.9 \pm 5.6$ & $33.6 \pm 1.6^{\#}$ & $29.4 \pm 4.7^{\#}$ & $81.9 \pm 4.1$ & $43.4 \pm 2.3^{\#}$ & $28.6 \pm 2.8^{\#}$ & $21.5 \pm 2.4^{\#}$ \\
\hline DG & $68.9 \pm 3.1$ & $51.6 \pm 3.7^{*}$ & $51.4 \pm 5.5$ & $34.9 \pm 2.5^{\#}$ & $30.5 \pm 3.4^{\#}$ & $89.8 \pm 4.8$ & $49.3 \pm 2.5^{\#}$ & $34.5 \pm 2.6^{\#}$ & $26.9 \pm 2.8^{\#}$ \\
\hline
\end{tabular}

See Figure 1 for abbreviations.

${ }_{P}<<0.05$

${ }^{\#} P<0.001$ treatment versus control (repeated measures two way ANOVA (treatment $\mathrm{x}$ brain region) followed by Bonferroni's post hoc tests, $n=6$ per group)

Bonferroni's post hoc tests were performed to compare binding in the different dosage groups $(25,50$, and $100 \mu \mathrm{g} / \mathrm{kg}$ HU210) with controls, within the various brain regions examined. Data from animals injected with the acute dose of $100 \mu \mathrm{g} / \mathrm{kg}$ HU210 was compared to controls in a separate two-way ANOVA followed by Bonferroni's post hoc tests.

Body weight over time was analyzed using a two way ANOVA (body weight $\times$ time) with repeated measures and Bonferroni's post hoc tests. Animals injected with the acute dose of $100 \mu \mathrm{g} / \mathrm{kg}$ HU210 on Day 4 were not included in the body weight analysis. Pearson correlations were used to investigate the relationship between body weight and radioligand binding in different brain regions in animals treated for 4 and 14 days. Data was analyzed using the SPSS 15.0 for Windows (IL, USA) and GraphPad Prism (CA, USA) statistical packages.

\section{RESULTS \\ $\left[{ }^{3} \mathrm{H}\right] \mathrm{CP55,940}$ binding in adolescent rats following acute, subchronic and chronic administration of HU210}

Region specific differences in $\left[{ }^{3} \mathrm{H}\right] \mathrm{CP} 55,940$ binding densities were seen in control animals (Fig. 1, Table I). In animals that received vehicle for 14 days for example, the globus pallidus, lateral caudate putamen and substantia nigra showed a high number of CB1 receptors with binding densities of $108.9 \pm 8,113.0 \pm 3$, and $239.9 \pm 11 \mathrm{fmol} / \mathrm{mg}$ TE respectively. Lower CB1 receptor densities of $45.8 \pm 3,46.1 \pm 2$ and $47.1 \pm 3 \mathrm{fmol} / \mathrm{mg}$ $\mathrm{TE}$ were seen in other brain regions such as the retrosplenial cortex, olfactory tubercle and thalamus, respectively (Table I).

After a single, acute dose of HU210 (vehicle for three days and $100 \mu \mathrm{g} / \mathrm{kg}$ HU210 on Day 4), two way ANOVA revealed a statistically significant variation in $\left[{ }^{3} \mathrm{H}\right] \mathrm{CP} 55,940$ binding with HU210 treatment $(F(1$, $140)=11.26, P=0.0073)$ and brain region $(F(14$, $140)=406.5, P<0.0001)$. A significant interaction between these two variables was not found. Bonferroni post hoc tests revealed statistically significant decreases in binding in the lateral caudate putamen $(20.2 \%, P<0.05)$ and dentate gyrus $(25.1 \%, P<0.05$; Figs. 1 and 2, Table I).

In animals treated for four days with HU210, a dose-dependent and brain region-specific downregulation in $\left[{ }^{3} \mathrm{H}\right] \mathrm{CP} 55,940$ binding was observed (Fig. 2; Table I). Statistical analysis showed that there was significant variation in $\left[{ }^{3} \mathrm{H}\right] \mathrm{CP} 55,940$ binding with HU210 treatment $(F(3,280)=25.31, P<0.0001)$ and brain region $(F(14,280)=409.9, P<0.0001)$, with a significant interaction between these two variables $(F(42,280)=4.255, P<0.0001)$. The greatest reductions in $\left[{ }^{3} \mathrm{H}\right] \mathrm{CP} 55,940$ binding were seen in animals treated with the highest dose of HU210, $100 \mu \mathrm{g} / \mathrm{kg}$. Within the $100 \mu \mathrm{g} / \mathrm{kg}$ group, the smallest, statistically significant reductions compared to controls were seen in the globus pallidus $(38.9 \%, P<0.001)$ and substantia nigra $(39.2 \%, P<0.001)$. The greatest reductions in binding were seen in the dentate gyrus $(55.7 \%$, $P<0.001)$ and CA1 $(56.7 \%, P<0.001)$ regions of the hippocampus (Fig. 2; Table I). In animals treated with $50 \mu \mathrm{g} / \mathrm{kg}$ HU210, statistically significant reductions in $\left.{ }^{3} \mathrm{H}\right] \mathrm{CP} 55,940$ binding compared to controls ranged from 24.5 to $50.6 \%(0.05<P<0.001)$. As in the $100 \mu \mathrm{g} / \mathrm{kg}$ treatment group, the smallest and largest decreases in binding were observed in the substantia nigra $(24.5 \%, P<0.001)$ and CA1 $(50.6 \%$, $P<0.001$ ), respectively. In the $50 \mu \mathrm{g} / \mathrm{kg}$ group, statistically significant reductions in binding were not observed in any of the cortical regions examined or in the nucleus accumbens, basolateral amygdala, olfactory tubercle and thalamus (Fig. 2; Table I). In animals treated with the lowest dose of HU210, 

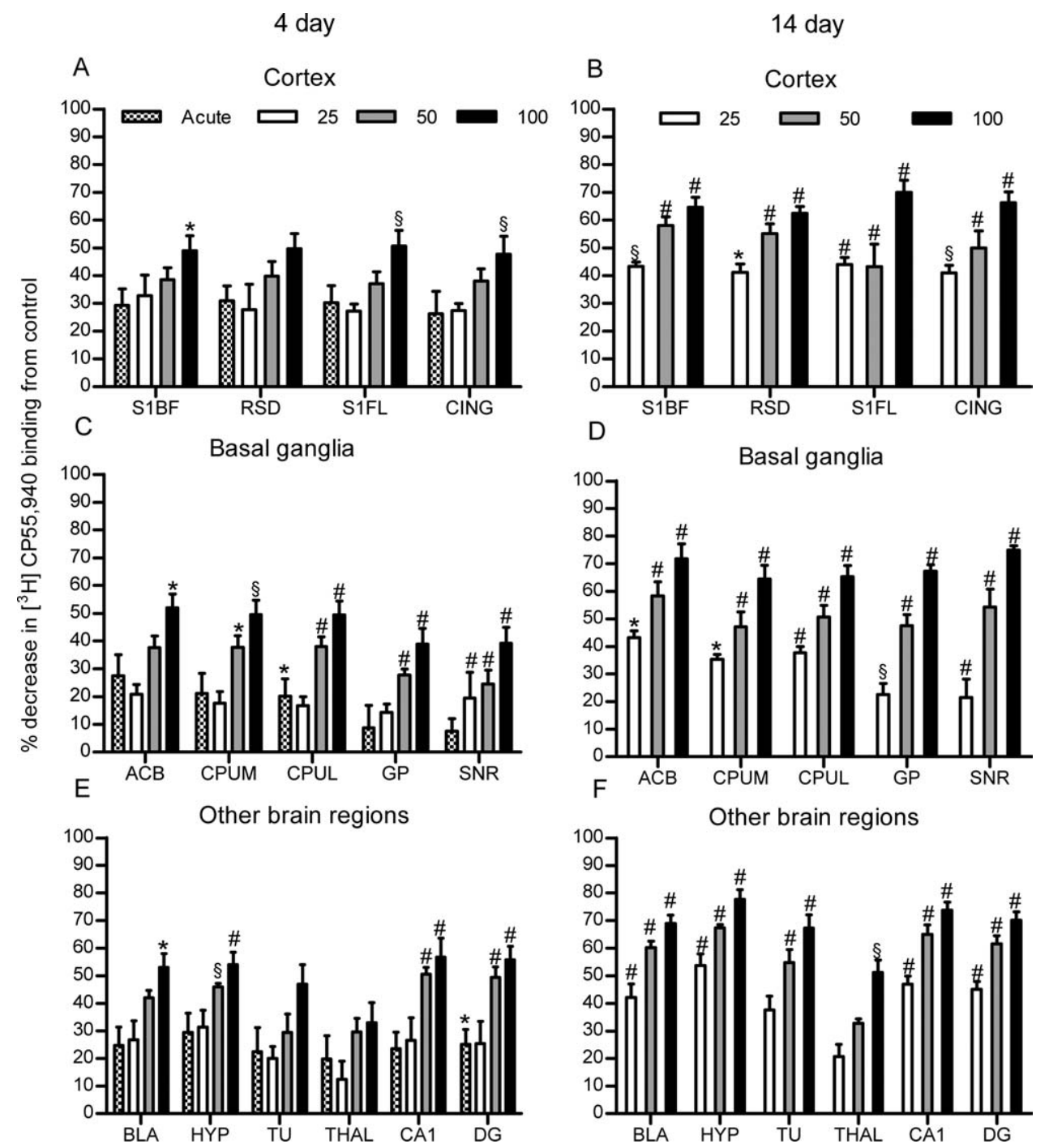

Fig. 2. Percentage decrease in $\left[{ }^{3} \mathrm{H}\right]$ CP55,940 binding density from control levels in adolescent rats treated with HU210 in cortical (A and $\mathbf{B}$ ), basal ganglia $(\mathbf{C}$ and $\mathbf{D})$ and other brain ( $\mathbf{E}$ and $\mathbf{F}$ ) regions. A, C, E: Animals received a single dose of $100 \mu \mathrm{g} / \mathrm{kg} \mathrm{HU} 210$ (acute) or were treated with 25, 50, or $100 \mu \mathrm{g} / \mathrm{kg}$ doses of HU210 for

$25 \mu \mathrm{g} / \mathrm{kg}$, the substantia nigra was the only region in which a statistically significant decrease of $19.4 \%(P$ $<0.001)$ compared with controls in $\left[{ }^{3} \mathrm{H}\right] \mathrm{CP} 55,940$ binding was found.

Following 14 days of HU210 administration, a dosedependent and brain region-specific downregulation in $\left[{ }^{3} \mathrm{H}\right]$ CP55,940 binding was also observed (Figs. 1 and 2; Table I) which was reflected by statistically significant variation in $\left[{ }^{3} \mathrm{H}\right] \mathrm{CP} 55,940$ binding with HU210 treatment $(F(3,280)=96.57, P<0.0001)$ and brain region $(F(14,280)=282.7, P<0.0001)$, with a significant interaction between these two variables $(F(42,280)=22.36, P<0.0001)$. As in animals treated for four days, the greatest reduction in $\left[{ }^{3} \mathrm{H}\right]$ CP55,940 binding was observed in animals that received $100 \mu \mathrm{g} / \mathrm{kg}$ HU210 for 14 days (Figs. 1 and 2; Table I). Compared with controls, the smallest reduction in binding in the $100 \mu \mathrm{g} / \mathrm{kg}$ group was observed in the thalamus $(51.1 \%, P<0.01)$ and the retrosplenial cortex $(62.4 \%, P<0.001)$. The largest decrease in binding was observed in the substantia nigra (74.9\%, $P<0.001)$ and hypothalamus $(77.7 \%, P<$ 0.001). Statistically significant reductions in binding were found in all brain regions in animals treated with $50 \mu \mathrm{g} / \mathrm{kg}$ for 14 days except in the thalamus (Figs. 1 and 2; Table I). Within this group, the smallest decreases in binding compared to controls were observed in the forelimb field of the primary somatosensory cortex $(43.1 \%, P<0.001)$ and medial caudate putamen $(47.2 \%, P<0.001)$, and the largest reduc- 


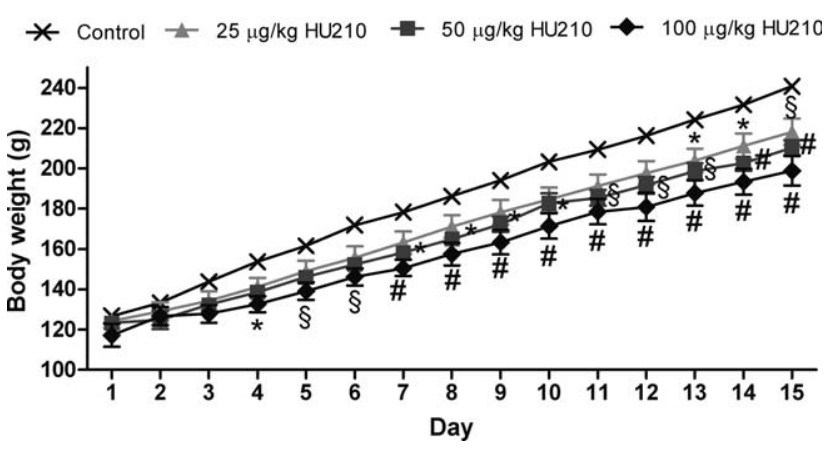

Fig. 3. Average body weight in grams (g) \pm SEM of adolescent rats receiving an intraperitoneal (i.p.) injection of 25,50 , or $100 \mu \mathrm{g} / \mathrm{kg}$ HU210 or vehicle (control) for 14 days. ${ }^{*} P<0.05, \S P<0.01$, \#P<0.001 (two way repeated measure ANOVA across time and Bonferroni's post hoc tests to compare the weight of treated animals with controls, $n=6$ per group).

tions were seen in the CA1 region of the hippocampus (65.0\%, $P<0.001)$ and hypothalamus $(67.5 \%, P<$ 0.001). In animals treated with $25 \mu \mathrm{g} / \mathrm{kg}$ HU210 for 14 days, statistically significant reductions in binding were observed in all brain regions except the thalamus and olfactory tubercle (Figs. 1 and 2; Table I). The lowest reductions in binding compared to controls, were found in the substantia nigra $(21.4 \%, P<$ $0.001)$ and globus pallidus $(22.6 \%, P<0.01)$. The greatest decreases within this group were observed in the CA1 region of the hippocampus $(47.0 \%, P<$ $0.001)$ and the hypothalamus $(53.7 \%, P<0.001)$.

\section{Body weight}

Control rats gained weight at an average rate of $5 \%$ per day over the course of 14 days treatment (Fig. 3). HU210 treatment was found to have a significant effect on body weight over time after $4(F(12,80)=$ $3.06, P=0.0001)$ and 14 days $(F(42,280)=1.25, P=$ 0.0001 ). In animals treated with HU210 for 14 days, an average increase in body weight in every group was recorded daily over the course of treatment. Body weight gain was slowest in the $100 \mu \mathrm{g} / \mathrm{kg}$ treatment group and improved in the dose-dependent manner, with the control group showing the greatest weight gain over the treatment period (Fig. 3). On Day 15, the average body weights of animals in the 25,50 , and $100 \mu \mathrm{g} / \mathrm{kg}$ HU210 groups remained lower than controls by $9.4 \%(P<0.01), 12.7 \%(P<0.001)$, and $17.4 \%(P<0.001)$, respectively (Fig. 3$)$. A similar trend in body weight gain was observed in animals that received HU210 for four days only (data not shown). Animals in the acute group gained weight over the course of the study but showed a slight (4\%) decrease in body weight $24 \mathrm{~h}$ after the acute dose of $100 \mu \mathrm{g} / \mathrm{kg}$ HU210 (data not shown).

In animals treated for four days with HU210, significant positive correlations $(0.459<r<0.412$, $0.045<P<0.024)$ were found between body weight on the day of sacrifice and $\left[{ }^{3} \mathrm{H}\right] \mathrm{CP} 55,940$ binding in the retrosplenial cortex, globus pallidus, and CA1 and dentate gyrus of the hippocampus in groups treated with 25,50 , and $100 \mu \mathrm{g} / \mathrm{kg}$ HU210 and controls. Significant positive correlations between body weight on the day of sacrifice and $\left[{ }^{3} \mathrm{H}\right] \mathrm{CP} 55,940$ binding in all brain regions $(0.854<r<0.690, P<0.0001)$ were also found in animals treated for 14 days (Fig. 4).

\section{DISCUSSION}

The main outcomes of this study are as follows: (a) Adolescent animals continue to put on weight during treatment with HU210 over a period of 14 days. Weight gain was slowest however in the $100 \mu \mathrm{g} / \mathrm{kg}$ group and improved dose dependently with controls gaining the most weight. (b) Adolescent animals dosedependently decrease their cannabinoid CB1 receptor following acute, subchronic, and chronic treatment with the synthetic cannabinoid HU210. The dose-dependent nature of the decrease is supported by the positive correlation observed between body weight and $\left[{ }^{3} \mathrm{H}\right] \mathrm{CP} 55,940$ binding in all brain regions after 14 days. (c) The magnitude of $\mathrm{CB} 1$ receptor downregulation was smaller in adolescent animals compared with adults treated under the same paradigm in our laboratory (Dalton et al., 2009) and tolerance to the weight loss inducing effects of HU210 developed more rapidly in adolescent animals (present study) compared with adults (Dalton et al., 2009).

Following the acute dose of HU210, statistically significant decreases in $\left[{ }^{3} \mathrm{H}\right] \mathrm{CP} 55,940$ binding in the adolescent brain were observed in the dentate gyrus of the hippocampus and lateral caudate putamen. In the adult rodent brain, following acute and short term cannabinoid treatment, significant decreases are seen in the hippocampus, lateral caudate putamen but also in the deep cortical layers (Dalton et al., 2009; Romero et al., 1997, 1998).

After subchronic and chronic HU210 treatment, we observed a dose-dependent decrease in $\left[{ }^{3} \mathrm{H}\right] \mathrm{CP} 55,940$ binding across brain regions. In addition, two-way ANOVA identified a significant interaction between treatment and brain region indicating that regionalspecific differences occur in CB1 receptor downregulation in the adolescent brain. The greatest decreases took place in the hypothalamus and hippocampus with the least reduction in the globus pallidus and substantia nigra. Downregulation of the CB1 receptor continues progressively over time since $\left[{ }^{3} \mathrm{H}\right] \mathrm{CP} 55,940$ binding in the 14 day treatment groups was lower than in the acute and 4 day groups in the majority of brain regions examined. Our findings are inline with the two other studies investigating CB1 receptor adaptation in adolescents after a high dose of the cannabinoid, THC (Craig et al., 2007; Rubino et al., 2008). 

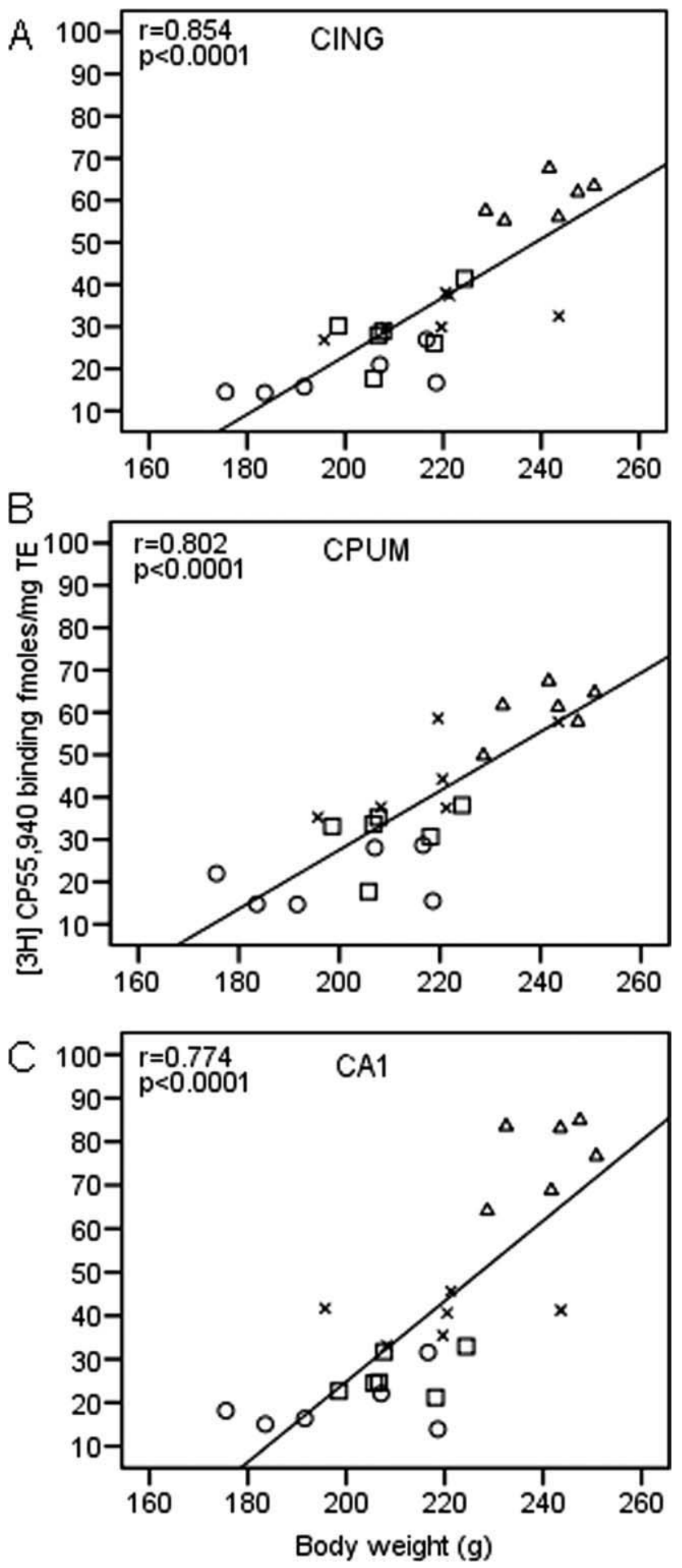

Fig. 4. Positive associations between $\left[{ }^{3} \mathrm{H}\right] \mathrm{CP} 55,940$ binding density [fmoles/mg tissue equivalent (TE)] and body weight in grams $(\mathrm{g})$ in adolescent animals treated for 14 days with 25,50 , or $100 \mu \mathrm{g} / \mathrm{kg}$ doses of HU210 or vehicle control. A: Pearson correlation between binding in the cingulate cortex (CING) and body weight, $r=0.854, P<0.0001$. B: Pearson correlation between binding in the medial caudate putamen (CPUM) and body weight, $r=0.802$, $P<0.0001$. C: Correlation between binding in the CA1 region of the hippocampus (CA1), $r=0.774, P<0.0001 . \Delta$ : control; x: $25 \mu \mathrm{g} / \mathrm{kg}$ HU210; $\square: 50 \mu \mathrm{g} / \mathrm{kg}$ HU210; O: $100 \mu \mathrm{g} / \mathrm{kg} \mathrm{HU} 210$.
On the basis of our results and those of Rubino et al. (2008), it appears that the largest and smallest reductions in $\mathrm{CB} 1$ receptor density occur in the same brain regions in the adolescent and adult male rodent brain (Dalton et al., 2009; Romero et al., 1997, 1998; Rubino et al., 2008; Sim-Selley, 2003). In general, however, it seems that the magnitude of $\mathrm{CB} 1$ receptor downregulation is smaller in the adolescent rodent brain compared to the adult (Dalton et al., 2009; Ellgren et al., 2007; Oviedo et al., 1993; Romero et al., 1997; Rubino et al., 2008). For example, the magnitude of the reduction in $\mathrm{CB} 1$ receptor downregulation was smaller in adolescents than in adults treated under the same paradigm in our laboratory (Dalton et al., 2009) by $3-33 \%$ in the acute group and by an average across doses of $10-16 \%$ in rats treated for 4 days and $6-28 \%$ in rats treated for 14 days. Furthermore, in contrast to adult rats treated with HU210 (Dalton et al., 2009), the acute and the lower doses of HU210 (25 and $50 \mu \mathrm{g} / \mathrm{kg}$ ) administered for four days elicited few statistically significant decreases in $\left[{ }^{3} \mathrm{H}\right] \mathrm{CP} 55,940$ binding in the male adolescent rat brain.

The underlying reasons are yet to be investigated for the smaller decrease in CB1 receptor density seen in the adolescent brain when compared to adults. It is unlikely though that this finding can be contributed solely to ontogenic variation in CB1 receptor levels since few significant differences were detected when $\left[{ }^{3} \mathrm{H}\right] \mathrm{CP} 55,940$ binding was compared in adolescent (PND 49; current study) and adult (PND 75; Dalton et al., 2009) control animals. Furthermore, the results of a study by Rodríguez de Fonseca et al. (1993) suggest that $\mathrm{CB} 1$ receptor density in the rat brain peaks at PND 40 and then declines slightly to reach stable levels in adulthood (PND 70).

It is also unlikely that the variation in $\left[{ }^{3} \mathrm{H}\right]$ CP55,940 binding in adults and adolescents is due exclusively to pharmacokinetic factors such as differences in drug absorption, distribution, biotransformation and excretion (Fox et al., 2009; González et al., 2005; Pandolfo et al., 2007). The results of studies comparing the acute behavioral effects of cannabinoid administration in adolescent and adult animals suggest an effective impact of the drug during the testing period in both adolescent and adult cohorts (Fox et al., 2009; Pandolfo et al., 2007).

Instead, emerging studies suggest that variations in receptor signaling cascade activation and pathways in the adolescent and adult rodent brain may, in part, account for the differential effects of cannabinoids on CB1 receptor downregulation observed in this study (Quinn et al., 2008; Rubino et al., 2009; Wegener and Koch, 2009). It has been shown for example that the protein expression profiles differ in the adolescent and adult brain after THC exposure (Quinn et al., 2008; Rubino et al., 2009). In addition, the expression of c-fos differs from controls in the brain of adult rats 
exposed the cannabinoid, WIN 55,212-2, during adolescence (Wegener and Koch, 2009).

Previous studies in adult rodents have indicated that tolerance to the behavioral effects of HU210 develops after repeated exposure to the drug (Ottani and Giuliani, 2001). In the present study, we used body weight as an indicator of the development of tolerance to HU210 in the adolescent rats. In adult animals, the development of tolerance to cannabinoid induced effects has been linked, in part, to a downregulation in CB1 receptor density (Dalton et al., 2009; Sim-Selley, 2003). Following acute exposure to HU210 in adolescents, we observed a smaller decrease in CB1 receptor density compared to adults (Dalton et al., 2009). In the hypothalamus for example, a region that is important in the endocannabinoidrelated control of body weight, metabolism, and stress responses (Romero et al., 2002b; Viveros et al., 2008), the magnitude of $\mathrm{CB} 1$ receptor downregulation was $18 \%$ lower in adolescents than in adults treated under the same regime (Dalton et al., 2009). In this study, however, tolerance to the weight loss inducing effects of HU210 developed more rapidly in adolescent animals compared with adults (Dalton et al., 2009; Giuliani et al., 2000). Throughout the treatment periods of 4 and 14 days, adolescents gained weight on every treatment day. In contrast, in adult rats, even taking into account a $4 \%$ slower growth rate than in adolescents (Dalton et al., 2009; Giuliani et al., 2000; Lamota et al., 2008; current study), HU210 causes weight loss for the first three to four treatment days (Dalton et al., 2009; Giuliani et al., 2000). Similarly, high doses of THC are associated with weight loss in adult animals for the first four treatment days (Verberne et al., 1980) but adolescents continue to gain weight daily over the course of THC treatment (Rubino et al., 2008).

In contrast to our findings in the hypothalamus, levels of CB1 receptor downregulation were similar in the basal ganglia (involved in locomotion; Monory et al., 2007; van der Stelt and Di Marzo, 2003) in adolescents and adults after the acute dose of HU210 but others have shown that adolescents are less sensitive to the acute locomotor reducing effects of cannabinoids (Schramm-Sapyta et al., 2007; Wiley et al., 2007). Tolerance to other responses to cannabinoids (antinociception, hypothermia, anxiety) also develops at different rates in adolescent and adult rats (Wiley et al., 2007).

The relationship in adolescents between CB1 receptor downregulation and body weight is evidenced by the strong positive correlation we observed between body weight and $\left[{ }^{3} \mathrm{H}\right] \mathrm{CP} 55,940$ binding after 14 days. Our findings in relation to acute CB1 receptor downregulation however suggest that other factors also influence the early development of tolerance to the weight loss inducing effects of HU210, and possibly other responses to cannabinoids, in adolescent animals. Along with receptor downregulation, cannabinoid tolerance in adult animals is also associated with receptor desensitization (Sim-Selley, 2003). Although sex-dependent differences following THC exposure have been described in adolescent rats (Craig et al., 2007; Rubino et al., 2008), a direct comparison examining CB1 receptor G-protein coupling in the adolescent and adult brain following cannabinoid treatment is yet to be published. Variations in the maturity of brain circuits modulated by the endocannabinoid system and other cannabinoid sensitive receptors (e.g., peroxisome proliferator activated receptors; Kota et al., 2005; O'Sullivan, 2007; Sébert et al., 2005) may also influence the short-term response of adolescents to cannabinoid treatment (Fox et al., 2009; Spear and Brake, 1983).

In humans, early cannabis use may increase the risk of overuse and addiction to more harmful drugs of abuse in later life (Realini et al., 2009). In adolescent rodents, cannabinoids have been shown to decrease the sensitivity to some illicit substances (Biscaia et al., 2008; Ellgren et al., 2007; Pistis et al., 2004). Adolescent exposure to THC and CP55,940 for example increases opiate intake in adult male rats and is associated with alterations in the endogenous opioid system in brain regions known to modulate reward behavior (Biscaia et al., 2008; Ellgren et al., 2007). WIN 55,212-2 exposure during adolescence in rats causes a long-lasting, decreased response of dopaminergic neurons of the ventral tegmental area to morphine, amphetamine and cocaine not seen in adult animals treated in parallel (Pistis et al., 2004). In the current study, we observed CB1 receptor downregulation in regions that constitute the primary motivational circuits in the brain thought to be involved in drug addiction including the nucleus accumbens, caudate putamen, amygdala, hippocampus, and thalamus (van der Stelt and Di Marzo, 2003; Chambers et al., 2003). As mentioned above though, the magnitude of CB1 downregulation was lower by 10-33\% after acute and 6-28\% after longer-term treatment in these structures than in adults (Dalton et al., 2009). Taking into account the neuromodulatory role of the endocannabinoid system, it is possible that a smaller CB1 downregulation in the adolescent brain compared with adults leads to age-specific alterations to the drug response in the primary motivational circuits such as the blunted reaction of dopaminergic neurons to pharmacological stimuli observed by Pistis et al. (2004) following adolescent cannabinoid exposure.

The smaller reduction in $\mathrm{CB} 1$ receptor density in adolescents compared to adults may also have implications for the longer-term effects of cannabinoid exposure such as deficits in memory and attention, and the development of psychosis (Ehrenreich et al., 1999; 
Luzi et al., 2008; O'Shea et al., 2004; Quinn et al., 2008; Schneider and Koch, 2003; Schneider et al., 2008). The G-protein family of receptors, which include the CB1 receptor, display downregulation after a repeated or long-lasting stimulus, the purpose of which is to reduce the effect of the stimulus and maintain biological equilibria (Lohse, 1993). The reduced compensatory response in adolescent brain regions such as the hippocampus and cortex may lead to higher stimulation of the $\mathrm{CB} 1$ receptor during the treatment period in comparison to adults. This in turn could have adverse effects on the plastic changes taking place in the adolescent brain given the interaction between the endocannabinoid system and other neurotransmitter signaling pathways during this important developmental phase (Rubino and Parolaro, 2008; Schneider, 2008). Indeed, following adolescent THC treatment for example, changes in hippocampal morphology, neuroplasticity, and protein expression that are associated with cognitive impairment in adulthood have been reported (Quinn et al., 2008; Rubino et al., 2009).

In conclusion, tolerance to the body weight loss inducing effects of the synthetic cannabinoid, HU210, develops faster in adolescents than in adults. The reduction of the CB1 receptor density following HU210 treatment however is smaller in magnitude in adolescent rats than in adults. The implications of this difference in downregulation require further investigation but may be a contributory factor in the acute behavioral effects, pharmacological cross-tolerance, and long-lasting behavioral deficits observed following adolescent cannabinoid exposure.

\section{ACKNOWLEDGMENTS}

The authors thank Ms. Hongqin Wang for technical assistance.

\section{REFERENCES}

Andersen SL. 2003. Trajectories of brain development: Point of vulnerability or window of opportunity? Neurosci Biobehav Rev 27: 3-18.

Biscaia M, Fernández B, Higuera-Matas A, Miguéns M, Viveros MP, García-Lecumberri C, Ambrosio E. 2008. Sex-dependent effects of periadolescent exposure to the cannabinoid agonist CP-55,940 on morphine self-administration behaviour and the endogenous opioid system. Neuropharmacology 54:863-873.

Breivogel CS, Childers SR. 1998. The functional neuroanatomy of brain cannabinoid receptors. Neurobiol Dis 5(Part B):417-431.

Breivogel CS, Childers SR, Deadwyler SA, Hampson RE, Vogt LJ, Sim-Selley LJ. 1999. Chronic delta9-tetrahydrocannabinol treatment produces a time-dependent loss of cannabinoid receptors and cannabinoid receptor-activated $\mathrm{G}$ proteins in rat brain. $\mathrm{J}$ Neurochem 73:2447-2459.

Chambers RA, Taylor JR, Potenza MN. 2003. Developmental neurocircuitry of motivation in adolescence: A critical period of addiction vulnerability. Am J Psychiatry 160:1041-1052.

Craig AA, Wiley JL, Burston JJ, Selley DE, Sim-Selly LJ. 2007. Effects of repeated administration of $\triangle 9$-THC on cannabinoid CB1 receptor density and function in adolescent and adult rats. 17th Annual Symposium on the Cannabinoids, Burlington, Vermont, International Cannabinoid Research Society, p82.
Dalton VS, Wang H, Zavitsanou K. 2009. HU210-induced downregulation in cannabinoid CB1 receptor binding strongly correlates with body weight loss in the adult rat. Neurochem Res 34:13431353.

Ehrenreich H, Rinn T, Kunert HJ, Moeller MR, Poser W, Schilling L, Gigerenzer G, Hoehe MR. 1999. Specific attentional dysfunction in adults following early start of cannabis use. Psychopharmacology (Berl) 142:295-301.

Ellgren M, Spano SM, Hurd YL. 2007. Adolescent cannabis exposure alters opiate intake and opioid limbic neuronal populations in adult rats. Neuropsychopharmacology 32:607-615.

Fox KM, Sterling RC, Van Bockstaele EJ. 2009. Cannabinoids and novelty investigation: Influence of age and duration of exposure. Behav Brain Res 196:248-253.

Fride E, Bregman T, Kirkham TC. 2005. Endocannabinoids and food intake: Newborn suckling and appetite regulation in adulthood. Exp Biol Med (Maywood) 230:225-234.

Giuliani D, Ottani A, Ferrari F. 2000. Effects of the cannabinoid receptor agonist. HU 210, on ingestive behaviour and body weight of rats. Eur J Pharmacol 391:275-279.

González S, Cebeira M, Fernández-Ruiz J. 2005. Cannabinoid tolerance and dependence: A review of studies in laboratory animals. Pharmacol Biochem Behav 81:300-318.

Izenwasser S. 2005. Differential effects of psychoactive drugs in adolescents and adults. Crit Rev Neurobiol 17:51-67.

Kota BP, Huang TH-W, Roufogalis BD. 2005. An overview on biological mechanisms of PPARs. Pharmacol Res 51:85-94.

Lamota L, Bermudez-Silva FJ, Marco E-M, Llorente R, Gallego A, Rodríguez de Fonseca F, Viveros M-P. 2008. Effects of adolescent nicotine and SR 147778 (Surinabant) administration on food intake, somatic growth and metabolic parameters in rats. Neuropharmacology 54:194-205.

Ledent C, Valverde O, Cossu G, Petitet F, Aubert J-F, Beslot F, Böhme GA, Imperato A, Pedrazzini T, Roques BP, Vassart G, Fratta W, Parmentier M. 1999. Unresponsiveness to cannabinoids and reduced addictive effects of opiates in CB1 receptor knockout mice. Science 283:401-404.

Lohse MJ. 1993. Molecular mechanisms of membrane receptor desensitization. Biochim Biophys Acta 1179:171-188.

Luzi S, Morrison PD, Powell J, di Forti M, Murray RM. 2008. What is the mechanism whereby cannabis use increases risk of psychosis? Neurotox Res 14(2-3):105-112.

Mechoulam R, Feigenbaum JJ, Lander N, Segal M, Järbe TUC, Hiltunen AJ, Consroe P. 1988. Enantiomeric cannabinoids: Stereospecificity of psychotropic activity. Experientia 44:762-764.

Monory K, Blaudzun H, Massa F, Kaiser N, Lemberger T, Schütz G, Wotjak CT, Lutz B, Marsicano G. 2007. Genetic dissection of behavioural and autonomic effects of $\operatorname{Delta}(9)$-tetrahydrocannabinol in mice. PLoS Biol 5:e269.

O'Shea M, Singh ME, McGregor IS, Mallet PE. 2004. Chronic cannabinoid exposure produces lasting memory impairment and increased anxiety in adolescent but not adult rats. J Psychopharmacol 18:502-508.

O'Sullivan SE. 2007. Cannabinoids go nuclear: Evidence for activation of peroxisome proliferator-activated receptors. $\mathrm{Br} \mathrm{J}$ Pharmacol 152:576-582.

Ottani A, Giuliani D. 2001. Hu 210: A potent tool for investigations of the cannabinoid system. CNS Drug Rev 7:131-145.

Oviedo A, Glowa J, Herkenham M. 1993. Chronic cannabinoid administration alters cannabinoid receptor binding in rat brain: A quantitative autoradiographic study. Brain Res 616(1-2):2933023.

Paxinos G, Watson C. 2007. The rat brain in stereotaxic coordinates. Sydney: Academic Press.

Pandolfo P, Pamplona FA, Prediger RDS, Takahashi RN. 2007. Increased sensitivity of adolescent spontaneously hypertensive rats, an animal model of attention deficit hyperactivity disorder, to the locomotor stimulation induced by the cannabinoid receptor agonist WIN 55,212-2. Eur J Pharmacol 563(1-3):141-148.

Pattij T, Wiskerke J, Schoffelmeer AN. 2008. Cannabinoid modulation of executive functions. Eur J Pharmacol 585(2-3):458-463.

Pistis M, Perra S, Pillolla G, Melis M, Muntoni AL, Gessa GL. 2004. Adolescent exposure to cannabinoids induces long-lasting changes in the response to drugs of abuse of rat midbrain dopamine neurons. Biol Psychiatry 56:86-94.

Quinn HR, Matsumoto I, Callaghan PD, Long LE, Arnold JC, Gunasekaran N, Thompson MR, Dawson B, Mallet PE, Kashem MA, Matsuda-Matsumoto H, Iwazaki T, McGregor IS. 2008. Adolescent rats find repeated delta(9)-THC less aversive than adult rats but display greater residual cognitive deficits and changes in hippocampal protein expression following exposure. Neuropsychopharmacology 33:1113-1126. 
Realini N, Rubino T, Parolaro D. 2009. Neurobiological alterations at adult age triggered by adolescent exposure to cannabinoids. Pharmacol Res 60:132-138.

Rodríguez de Fonseca F, Ramos JA, Bonnin A, Fernández-Ruiz JJ. 1993. Presence of cannabinoid binding sites in the brain from early postnatal ages. Neuroreport 4:135-138.

Romero J, Garcia-Palomero E, Castro JG, Garcia-Gil L, Ramos JA, Fernández -Ruiz JJ. 1997. Effects of chronic exposure to delta9-tetrahydrocannabinol on cannabinoid receptor binding and mRNA levels in several rat brain regions. Brain Res Mol Brain Res 46(1-2):100-108.

Romero J, Berrendero F, Manzanares J, Pérez A, Corchero J, Fuentes JA, Fernández -Ruiz JJ, Ramos JA. 1998. Time-course of the cannabinoid receptor down-regulation in the adult rat brain caused by repeated exposure to delta9-tetrahydrocannabinol. Synapse 30:298-308.

Romero J, Lastres-Becker I, de Miguel R, Berrendero F, Ramos JA, Fernández-Ruiz J. 2002a. The endogenous cannabinoid system and the basal ganglia. Biochemical, pharmacological, and therapeutic aspects. Pharmacol Ther 95:137-152.

Romero EM, Fernández B, Sagredo O, Gomez N, Urigüen L, Guaza C, De Miguel R, Ramos JA, Viveros MP. 2002b. Antinociceptive, behavioural and neuroendocrine effects of CP 55,940 in young rats. Brain Res Dev Brain Res 136:85-92.

Rubino T, Parolaro D. 2008. Long lasting consequences of cannabis exposure in adolescence. Mol Cell Endocrinol 286(1-2Suppl 1):S108-S113.

Rubino T, Viganò D, Realini N, Guidali C, Braida D, Capurro V, Castiglioni C, Cherubino F, Romualdi P, Candeletti S, Sala M, Parolaro D. 2008. Chronic delta(9)-tetrahydrocannabinol during adolescence provokes sex-dependent changes in the emotional profile in adult rats: Behavioral and biochemical correlates. Neuropsychopharmacology 33:2760-2771.

Rubino T, Realini N, Braida D, Guidi S, Capurro V, Viganò D, Guidali C, Pinter M, Sala M, Bartesaghi R, Parolaro D. 2009. Changes in hippocampal morphology and neuroplasticity induced by adolescent THC treatment are associated with cognitive impairment in adulthood. Hippocampus 19:763-772.

Schneider M. 2008. Puberty as a highly vulnerable developmenta period for the consequences of cannabis exposure. Addict Biol 13:253-263.

Schneider M, Koch M. 2003. Chronic pubertal, but not adult chronic cannabinoid treatment impairs sensorimotor gating, recognition memory, and the performance in a progressive ratio task in adult rats. Neuropsychopharmacology 28:1760-1769.

Schneider M, Schömig E, Leweke FM. 2008. Acute and chronic cannabinoid treatment differentially affects recognition memory and social behavior in pubertal and adult rats. Addict Biol 13(34):345-357.

Schramm-Sapyta NL, Cha YM, Chaudhry S, Wilson WA, Swartzwelder HS, Kuhn CM. 2007. Differential anxiogenic, aversive, and locomotor effects of THC in adolescent and adult rats. Psychopharmacology (Berl) 191:867-877.
Sébert SP, Lecannu G, Kozlowski F, Siliart B, Bard JM, Krempf M, Champ MM-J. 2005. Childhood obesity and insulin resistance in a Yucatan mini-piglet model: Putative roles of IGF-1 and muscle PPARs in adipose tissue activity and development. Int J Obes (Lond) 29:324-333.

Sigel E. 2008. Eating disorders. Adolesc Med State Art Rev 19:547572 .

Sim-Selley LJ. 2003. Regulation of cannabinoid CB1 receptors in the central nervous system by chronic cannabinoids. Crit Rev Neurobiol 15:91-119.

Sim-Selley LJ, Martin BR. 2002. Effect of chronic administration of R-(+)-[2,3-Dihydro-5-methyl-3-[(morpholinyl)methyl]pyrrolo[1,2,3de]-1,4-b enzoxazinyl]-(1-naphthalenyl)methanone mesylate (WIN55,212-2) or delta(9)-tetrahydrocannabinol on cannabinoid receptor adaptation in mice. J Pharmacol Exp Ther 303:36-44.

Spear LP. 2000. The adolescent brain and age-related behavioral manifestations. Neurosci Biobehav Rev 24:417-463.

Spear LP, Brake SC. 1983. Periadolescence: Age-dependent behavior and psychopharmacological responsivity in rats. Dev Psychobiol 16:83-109.

Trezza V, Cuomo V, Vanderschuren LJMJ. 2008. Cannabis and the developing brain: Insights from behavior. Eur J Pharmacol 585:441-452.

van der Stelt M, Di Marzo V. 2003. The endocannabinoid system in the basal ganglia and in the mesolimbic reward system: Implications for neurological and psychiatric disorders. Eur J Pharmacol 480(1-3):133-150.

Verberne AJM, Taylor DA, Fennessy MR. 1980. Withdrawal-like behaviour induced by inhibitors of biogenic amine reuptake in rats treated chronically with delta 9-tetrahydrocannabinol. Psychopharmacology (Berl) 68:261-267.

Viveros MP, Rodríguez de Fonseca F, Bermudez-Silva FJ, McPartland JM. 2008. Critical role of the endocannabinoid system in the regulation of food intake and energy metabolism, with phylogenetic, developmental, and pathophysiological implications. Endocr Metab Immune Disord Drug Targets 8:220-230.

Wang T, Collet JP, Shapiro S, Ware MA. 2008. Adverse effects of medical cannabinoids: A systematic review. CMAJ 178:1669-1678.

Wegener N, Koch M. 2009. Behavioural disturbances and altered Fos protein expression in adult rats after chronic pubertal cannabinoid treatment. Brain Res 1253:81-91.

Wiley JL, O'Connell MM, Tokarz ME, Wright MJ, Jr. 2007. Pharmacological effects of acute and repeated administration of $\operatorname{Delta}(9)$ tetrahydrocannabinol in adolescent and adult rats. J Pharmacol Exp Ther 320:1097-1105.

Wilson RI, Nicoll RA. 2002. Endocannabinoid signaling in the brain. Science 296:678-682.

Zimmer A, Zimmer AM, Hohmann AG, Herkenham M, Bonner TI. 1999. Increased mortality, hypoactivity, and hypoalgesia in cannabinoid CB1 receptor knockout mice. Proc Natl Acad Sci USA 96:5780-5785. 